\title{
LETTER
}

\section{Early versus late renal replacement therapy in acute kidney injury: the search for a definition of timing continues}

\author{
Jonathan Bannard-Smith* and Stephen Mousdale \\ See related research by Karvellas et al., http://ccforum.com/content/15/1/R72
}

\begin{abstract}
We read with interest the systematic review by Karvellas and colleagues on early versus late renal replacement therapy (RRT) in critically ill patients with acute kidney injury (AKI) [1]. The authors rightly cite enormous heterogeneity between the 15 studies reviewed as a key concern. We would like to focus on the varied approach and lack of consensus in defining early and late initiation of RRT, as all of the 15 studies quote different definitions in their methods. Even those utilising similar markers and criteria for AKI - for example, the RIFLE criteria [2] (two studies) or blood urea and nitrogen (four studies) utilised and interpreted them in very different ways when distinguishing early and late initiation of RRT.

None of the studies reviewed used the Acute Kidney Injury Network (AKIN) criteria [3]. Having applied the AKIN criteria to data from our 20-bed critical care unit for all patients receiving RRT in $2009(n=158)$, we also failed to show RRT initiated at an early stage of AKI to be of benefit in terms of critical care or hospital survival. Figure 1 shows a higher rate of hospital mortality in patients with AKIN stage 1 AKI $(P=0.01)$. Patient characteristics including age, sex and Acute Physiology and Chronic Health Evaluation scores were similar across all groups. In view of our experience and Karvellas and
\end{abstract}

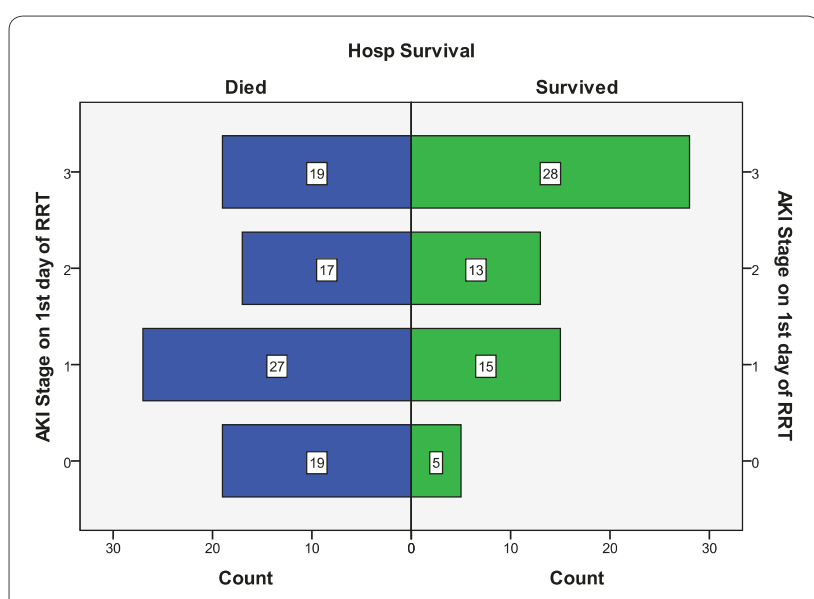

Figure 1. Hospital survival based on acute kidney injury staging. Histogram for hospital survival based on acute kidney injury (AKI) staging according to Acute Kidney Injury Network criteria [3] $(n=143)$. RRT, renal replacement therapy.

colleagues' conclusions, surely the matter of greatest urgency prior to any multicentre trial is establishing a satisfactory definition for early and late initiation of RRT.

\section{Authors' response}

Constantine J Karvellas and Sean M Bagshaw

We appreciate the comments by Bannard-Smith and Mousdale pertaining to our systematic review of early versus late initiation of RRT in critically ill patients with AKI [1]. Indeed, we found that the available literature to

*Correspondence: jonbannardsmith@doctors.org.uk

Department of Anaesthesia \& Critical Care, Royal Blackburn Hospital, Haslingden Road, Blackburn BB2 3HH, UK date is prohibitively heterogeneous, in particular with respect to study methodology, study quality and operational definitions of timing of RRT.

As mentioned, few studies included in our review utilised the RIFLE criteria to define timing. One study compared timing by fulfilling RISK versus INJURY or FAILURE categories in medical ICU patients [4], while the other compared RISK and INJURY versus FAILURE in surgical/trauma patients [5]. While no study specifically utilised the AKIN modifications of RIFLE to 
define timing, it is unlikely there are substantial differences between these classifications for the discrimination of timing or associated outcomes [6].

In part, this is attributed to the similarity of these classifications, both of which rely exclusively on changes in serum creatinine and urine output as defining features. This is clearly suboptimal when considering the complexity of the decision to initiate RRT in critically ill patients, where fluid, electrolyte, and acid-base homeostasis may only partially account for why RRT is initiated.

Accordingly, we contend that the optimal time to start RRT in critically ill patients with AKI associated with more favourable outcome is unknown. Undeniably, a first priority would be to generate new evidence and consensus guidance for establishing not only current standards of practice, but also reasonable operational definitions for early initiation. We also contend that the integration of novel specific kidney injury biomarkers showing added discrimination for the progression of AKI and need for RRT are likely to be essential to inform the design of future clinical trials on this issue [7].

\section{Abbreviations}

AKI, acute kidney injury; AKIN, Acute Kidney Injury Network; ICU, intensive care unit; RIFLE, Risk, Injury, Failure, Loss and End-stage kidney disease; RRT, renal replacement therapy.

\section{Competing interests}

The authors declare that they have no competing interests.

Published: 29 July 2011

\section{References}

1. Karvellas CJ, Farhat MR, Sajjad I, Mogensen SS, Leung AA, Wald R, Bagshaw SM: A comparison of early versus late initiation of renal replacement therapy in critically ill patients with acute kidney injury: a systematic review and meta-analysis. Crit Care 2011, 15:R72

2. Bellomo R, Ronco C, Kellum JA, Mehta RL, Palevsky P; ADQI workgroup: Acute renal failure - definition, outcome measures, animal models, fluid therapy and information technology needs: the Second International Consensus Conference of the Acute Dialysis Quality Initiative (ADQI) Group. Crit Care 2004, 8:R204-R212

3. Mehta RL, Kellum JA, Shah SV, Molitoris BA, Ronco C, Warnock DG, Levin A: Acute Kidney Injury Network: report of an initiative to improve outcomes in acute kidney injury. Crit Care 2007, 11:R31.

4. Sabater J, Perez XL, Albertos R, Gutierrez D, Labad X: Acute renal failure in septic shock. Should we consider different continuous renal replacement therapies on each RIFLE score stage? [Abstract.] Intensive Care Med 2009, 35:\$239.

5. Shiao CC, Wu VC, Li WY, Lin YF, Hu FC, Young GH, Kuo CC, Kao TW, Huang DM, Chen YM, Tsai PR, Lin SL, Chou NK, Lin TH, Yeh YC, Wang CH, Chou A, Ko WJ, Wu KD; National Taiwan University Surgical Intensive Care Unit-Associated Renal Failure (NSARF) Study Group : Late initiation of renal replacement therapy is associated with worse outcomes in acute kidney injury after major abdominal surgery. Crit Care 2009, 13:R171.

6. Bagshaw SM, George C, Bellomo R: A comparison of the RIFLE and AKIN criteria for acute kidney injury in critically ill patients. Nephrol Dial Transplant 2008, 23:1569-1574.

7. Haase M, Bellomo R, Devarajan P, Schlattmann P, Haase-Fielitz A: Accuracy of neutrophil gelatinase-associated lipocalin (NGAL) in diagnosis and prognosis in acute kidney injury: a systematic review and meta-analysis. Am J Kidney Dis 2009, 54:1012-1024.

\section{doi:10.1186/cc10275}

Cite this article as: Bannard-Smith J, Mousdale S: Early versus late renal replacement therapy in acute kidney injury: the search for a definition of timing continues. Critical Care 2011, 15:437. 